\title{
Bupivacaine administered intrathecally versus rectally in the management of intractable rectal cancer pain in palliative care
}

This article was published in the following Dove Press journal:

OncoTargets and Therapy

6 October 2014

Number of times this article has been viewed

\author{
Iwona Zaporowska- \\ Stachowiak ${ }^{1,2}$ \\ Grzegorz Kowalski ${ }^{3}$ \\ Jacek Łuczak ${ }^{2}$ \\ Katarzyna Kosicka ${ }^{4}$ \\ Aleksandra Kotlinska- \\ Lemieszek $^{3}$ \\ Maciej Sopata ${ }^{3}$ \\ Franciszek Główka ${ }^{4}$ \\ 'Chair and Department of \\ Pharmacology, Poznan University of \\ Medical Sciences, Poznan, Poland; \\ ${ }^{2}$ Palliative Medicine In-patient \\ Unit, University Hospital of Lord's \\ Transfiguration, Poznan University \\ of Medical Sciences, Poznan, Poland; \\ ${ }^{3}$ Palliative Medicine Chair and \\ Department, Poznan University of \\ Medical Sciences, Poznan, Poland; \\ ${ }^{4}$ Department of Physical Pharmacy \\ and Pharmacokinetics, Poznan \\ University of Medical Sciences, \\ Poznań, Poland
}

Background: Unacceptable adverse effects, contraindications to and/or ineffectiveness of World Health Organization step III "pain ladder" drugs causes needless suffering among a population of cancer patients. Successful management of severe cancer pain may require invasive treatment. However, a patient's refusal of an invasive procedure necessitates that clinicians consider alternative options.

Objective: Intrathecal bupivacaine delivery as a viable treatment of intractable pain is well documented. There are no data on rectal bupivacaine use in cancer patients or in the treatment of cancer tenesmoid pain. This study aims to demonstrate that bupivacaine administered rectally could be a step in between the current treatment options for intractable cancer pain (conventional/conservative analgesia or invasive procedures), and to evaluate the effect of the mode of administration (intrathecal versus rectal) on the bupivacaine plasma concentration.

Cases: We present two Caucasian, elderly inpatients admitted to hospice due to intractable rectal/tenesmoid pain. The first case is a female with vulvar cancer, and malignant infiltration of the rectum/vagina. Bupivacaine was used intrathecally $(0.25-0.5 \%, 1-2 \mathrm{~mL}$ every 6 hours). The second case is a female with ovarian cancer and malignant rectal infiltration. Bupivacaine was adminstered rectally $(0.05-0.1 \%, 100 \mathrm{~mL}$ every $4.5-11$ hours).

Methods: Total bupivacaine plasma concentrations were determined using the high-performance liquid chromatography-ultraviolet method.

Results: Effective pain control was achieved with intrathecal bupivacaine $\left(0.077-0.154 \mathrm{mg} \cdot \mathrm{kg}^{-1}\right)$ and bupivacaine in enema $\left(1.820 \mathrm{mg} \cdot \mathrm{kg}^{-1}\right)$. Intrathecal bupivacaine $(0.5 \%, 2 \mathrm{~mL})$ caused a drop in blood pressure; other side effects were absent in both cases. Total plasma bupivacaine concentrations following intrathecal and rectal bupivacaine application did not exceed 317.2 $\mathrm{ng} \cdot \mathrm{mL}^{-1}$ and $235.7 \mathrm{ng} \cdot \mathrm{mL}^{-1}$, respectively. Bupivacaine elimination was slower after rectal than after intrathecal administration $\left(\mathrm{t}_{1 / 2}=5.50\right.$ versus 2.02 hours, respectively).

Limitations: This study reports two cases only, and there could be inter-patient variation.

Conclusion: Bupivacaine in boluses administered intrathecally $(0.25 \%, 2 \mathrm{~mL})$ provided effective, safe analgesia in advanced cancer patients. Bupivacaine enema $\left(100 \mathrm{mg} \cdot 100 \mathrm{~mL}^{-1}\right)$ was shown to be a valuable option for control of end-of-life tenesmoid cancer pain.

Keywords: tenesmoid pain, intractable cancer pain, bupivacaine, intrathecal, palliative, local anesthetic, toxicity

\section{Introduction}

The World Health Organization (WHO) cancer pain ladder is supplemented by invasive procedures, to improve patients' quality of life and dying. This multimodal treatment provides pain relief for patients who fail the systemic therapy. ${ }^{1-4}$ Invasive procedures may be introduced on every step of the WHO cancer pain ladder, however, interventions
Stachowiak

Chair and Department of Pharmacology, Poznan University of Medical Sciences, Rokietnicka 25A, 60-806 Poznań, Poland Email iwozapor@amp.edu.pl 
aimed at relieving pain are frequently classified as the "last resort" or "second-tier and advanced procedures." They are considered to be the fourth ladder step by some authors. ${ }^{5-10}$

The introduction of the fourth ladder step was proposed as a result of the evidence showing that pain managed according to the WHO recommendations may be undertreated and cause needless suffering in some cases, including patients in palliative care. The European Society for Medical Oncology Clinical Practice Guidelines in cancer pain management state that $64 \%$ of advanced cancer or terminal patients suffer from pain and $\pm 50 \%$ of them are undertreated. ${ }^{11}$ In $10 \%$ of terminal patients who require parenteral treatment, the pain is refractory to conventional therapy. ${ }^{11}$ Unwanted effects or contraindications to systemic analgesics also limit their usefulness. A population of patients with a well-defined and localized pain may benefit from regional anesthesia: a central (neuraxial) or peripheral (neurolytic) block. ${ }^{12,13}$

Regional anesthetic techniques are effective and safe in $90 \%$ of cases; ${ }^{14}$ ie, in situations where the patients are properly selected and closely monitored, the dosage of coadministered opioid(s) is reduced, and the procedure is performed by skilled staff., 4

Neuraxial blocks' effectiveness stem from the fact that the pain is modulated with the participation of the spinal cord. Drugs that interact with presynaptic and postsynaptic receptors on cell membranes located in the spinal cord's dorsal horn are used for pain relief. ${ }^{16}$ These are agents exerting various pharmacodynamic effects: opioids, sodium channel blockers (local anesthetics [LAs]), gamma-aminobutyric-acid modulators (midazolam, baclofen), alpha-2-adrenergic agonists (clonidine, dexmedetomidine), a dissociative anesthetic (ketamine), a selective blocker of voltage-gated N-type calcium channels (ziconotide), ${ }^{13}$ nonsteroidal anti-inflammatory drugs, and other agents. ${ }^{15,17,18}$

High concentrations of these medicines in the spinal cord structures are generated by means of the spinal mode of the drugs' administration (central neuraxial block): either directly to the cerebrospinal fluid (CSF) (intrathecal drug delivery [IDD] or to the epidural space (epidurally (ED), to block the spinal nerve roots and make a drug diffuse across the dura, into the CSF). This kind of medication administration generates a very strong and satisfactory analgesia, with a small risk of side effects due to the drug's low plasma concentrations. ${ }^{15,19}$ Smith et al state that the intrathecal drug administration may improve survival in cancer patients. ${ }^{20}$

According to Kaplan, lidocaine and bupivacaine have been approved by the Food and Drug Administration (FDA) for intrathecal and epidural infusion. ${ }^{5}$ Hayek et al state that, although only preservative-free morphine and ziconotide are FDA-approved for the intrathecal treatment of chronic pain, bupivacaine is also widely used. ${ }^{21}$ Both continuous infusion and boluses of LAs are effective in pain management. ${ }^{8}$ However, close monitoring of LAs is still obligatory in every case, since this class of drugs does bring a risk of systemic toxicity. LAs are capable of blocking the action potential in all excitable tissues (via blockage of voltage-sensitive sodium channels), including sensory, motor, and sympathetic nerves, as well as, when in the form of toxic serum concentrations, the central nervous system (CNS) and heart muscle. Patients with advanced cancer disease constitute a heterogeneous group of subjects with an increased risk of LAs' neurotoxicity and cardiotoxicity, which may be fatal. ${ }^{22-24}$ This susceptibility to LA toxicity results from comorbidities (decreased organ reserves) and/or disturbances (hypoalbuminemia, hypocalcemia, hypovolemia, hypoxia, cardiovascular or CNS diseases, decreased hepatic blood flow, liver impairment, chronic renal disease, or drug-drug interactions, any of which can and do occur in most cases). LA's total daily doses, their plasma concentrations, and classic pharmacokinetics determine either the potential safety or systemic toxicity of a given drug. Bupivacaine is most commonly prescribed and its IDD dose must not exceed 30-60 mg daily (6-12 mL 0.5\%). Otherwise, the following side effects are increasingly probable: motor block, sedation, light-headedness, drowsiness, visual/auditory disturbances, circumoral/tongue numbness, incoherent speech, metallic taste, nystagmus, tinnitus, impaired respiratory activity, tremor, muscle twitching, seizures, urinary retention, bowel dysfunction, hypotension, arrhythmias, and cardiac arrest. ${ }^{25-27}$ Serious CNS toxicity and cardiotoxicity are rare. ${ }^{28}$ The response to the drugs depends on individual characteristics, especially when bupivacaine plasma concentrations exceed $10 \mathrm{mg} / \mathrm{L}$. Richardson et $\mathrm{al}^{28}$ proved that early systemic toxicity occurs at plasma levels of $2.5 \mathrm{mg} / \mathrm{L}$, so the safe level was stated to be less than $3 \mathrm{mg} / \mathrm{L} .{ }^{15}$ Bupivacaine, an amidetype LA, is biotransformed by the microsomal cytochrome CYP3A4, and to a lesser extent, by CYP2D6/CYP2C19 of $\mathrm{P} 450$ liver isoenzymes, into more water-soluble compounds (the main, less toxic, metabolite pipecolylxylidine constitutes $5 \%$ of the dose). ${ }^{29} \mathrm{~A}$ small amount of the unchanged drug is excreted in the urine. ${ }^{30}$ Liver disease, reduced hepatic blood flow, and coadministration of specific P450 competing drugs may slow down bupivacaine's metabolism.

Blocks with spinally administered LAs have very rapid onsets. A rapid, local analgesic effect may also be achieved by giving an LA rectally in a suitable solution. This may be considered an option, eg, when a patient decides against 
invasive treatment. The absorption from rectum to the rectal veins is sufficient even if its absorbing area is 10,000 times smaller than the one of the small intestine. While vessels from the upper part of the rectum join the portal vein, blood from the lower part is directly delivered to the systemic circulation. That is why high-clearance drugs' (eg, lidocaine's) hepatic first-pass elimination is reduced after rectal administration. ${ }^{31-32}$ Rectal lidocaine was successfully used in patients with irritable bowel syndrome. ${ }^{33}$ On the other hand, there are no available data on the use of LAs rectally in cancer pain. The pharmacokinetics of bupivacaine administered rectally also remains unknown.

The purpose of this paper is to demonstrate that rectal bupivacaine can serve as a safe and effective alternative to intrathecal analgesia in intractable tenesmoid cancer pain management. The secondary aim was to present findings as to bupivacaine's plasma concentrations following intrathecal and rectal drug administrations.

\section{Case reports Case I}

Case 1 was an 81-year-old woman with cancer of the vulva, admitted to the palliative medicine in-patient unit in the University Hospital of Lord's Transfiguration (Poznan', Poland) due to an extremely severe, intractable perineal and rectal tenesmoid pain (intensified by passive movements, eg, during nursing). The intensity of the pain was $10 / 10$ (Verbal Rating Scale [VRS], see Methods). The patient was in a poor condition, somnolent, unable to walk and sit, speaking reluctantly, yet oriented to person and place (for details see Table 1). She had dry mucous membranes in the oral cavity; a regular heart rate; a loud systolic heart murmur over the aortic valve; lungs clear to bilateral auscultation; and a soft abdomen, with normal active bowel sounds, not painful during palpation. Her body showed resistance in hypogastrium during palpation, her right lower extremity was swollen, perineum changes were visible macroscopically with an unpleasant smell, she had a bedsore on the left buttock, a catheter in the urinary bladder, constant stool incontinence, and dysphagia (only a liquid diet possible). Clinical characteristics of the patient and laboratory tests results are presented in Table 1.

\section{Pertinent medical history}

Cancer of the vulva (carcinoma planoepitheliale, partim keratodes) was diagnosed 19 months before admission to the hospice unit. Following that, radiotherapy was introduced. Infiltration on the rectum and vagina was detected 8 months
Table I Clinical characteristics and laboratory investigation results of Patient I

\begin{tabular}{|c|c|}
\hline Factor & Value/level \\
\hline \multicolumn{2}{|l|}{ Clinical characteristics } \\
\hline Age (years) & 81 \\
\hline BMI & 26 \\
\hline Karnofsky score & 30 \\
\hline ECOG & 4 \\
\hline $\mathrm{BPs}(\mathrm{mmHg})$ & 113 \\
\hline $\mathrm{BPd}(\mathrm{mmHg})$ & 90 \\
\hline Heart rate $(\mathrm{I} /$ minute $)$ & 86 \\
\hline Respiratory rate (I/minute) & 14 \\
\hline $\mathrm{SpO} 2(\%)$ on room air & 90 \\
\hline eGFR $\left(\mathrm{mL} / \mathrm{min} / \mathrm{I} .73 \mathrm{~m}^{2}\right)^{*}$ & 23 \\
\hline \multicolumn{2}{|l|}{ Laboratory investigations } \\
\hline Albuminaemia $(\mathrm{g} / \mathrm{L})$ & 19.80 \\
\hline WBC (10e9/L) & 16.35 \\
\hline $\mathrm{Hb}(\mathrm{mM})$ & 7.30 \\
\hline HTC (L/L) & 0.36 \\
\hline PLT (I0e9/L) & 414 \\
\hline Creatinine in serum $(\mu \mathrm{M})$ & 326.50 \\
\hline Urea in serum $(\mathrm{mM})$ & 29.69 \\
\hline Calcium in serum $(\mathrm{mM})$ & 3.25 \\
\hline $\operatorname{ALAT}(\mathrm{U} / \mathrm{L})$ & 36 \\
\hline AspAT (U/L) & 75 \\
\hline PT time (seconds) & 11.00 \\
\hline PT indicator (\%) & 100 \\
\hline INR & 1.00 \\
\hline
\end{tabular}

Note: *eGFR was calculated by the MDRD formula.

Abbreviations: ALAT, alanine aminotransferase; AspAT, aspartate aminotransferase; BMI, body mass index; BPs, systolic blood pressure; BPd, diastolic blood pressure; ECOG, Eastern Cooperative Oncology Group scale performance score; eGFR, estimated glomerular filtration rate; Hb, hemoglobin; HTC, hematocrit; INR, international normalized ratio; MDRD, Modification of Diet in Renal Disease formula; PLT, platelets; PT, prothrombin; SpO2, blood oxygen saturation; WBC, white blood cells.

later. The recurrence and rectovaginal septum were removed surgically.

\section{Concomitant diseases}

Arterial hypertension, aortic stenosis, cholelithiasis, suspected pubic bone fracture, and deep vein thrombosis of right lower extremity were diagnosed 2 months before admission.

\section{Drugs taken prior to admission}

Prior to admission, the patient took the following drugs: fentanyl in transdermal formulation releasing $50 \mathrm{mcg} / \mathrm{h}$, morphine sulphate, immediate release formulation $10 \mathrm{mg}$ orally every 4 hours, enoxaparin $40 \mathrm{mg}$ subcutaneously once a day, isosorbide mononitrate $80 \mathrm{mg}$ orally daily in divided doses, lithium carbonate $1.25 \mathrm{mg}$ orally daily in divided doses, trimetazidine $60 \mathrm{mg}$ orally daily in divided doses, mianserin $30 \mathrm{mg}$ orally daily, and ketoprofen $300 \mathrm{mg}$ orally in divided doses. 


\section{Hospice treatment}

Systemic fentanyl did not serve as effective analgesia. As the symptoms were spectacular, response to pain was extreme (the patient reacted with a scream to any physical contact); and as interventional doses of intravenous (IV) morphine sulfate, propofol IV, and midazolam IV were ineffective, we decided upon interventional pain management: intrathecal administration of bupivacaine.

\section{Case 2}

Case 2 was an 83-year-old woman with ovarian cancer, admitted to the palliative medicine in-patient unit in the University Hospital of Lord's Transfiguration (Poznań, Poland) due to severe, well-localized, tenesmoid pain, serious discomfort while sitting, weakness, and anorexia. The patient complained about vertigo, flatulence, and urine incontinence. On admission, the patient was very weak, oriented to person and place, and emotionally tense, with lean subcutaneous fat, an irregular heart rate, and a soft pulse (for details see Table 2). Her

Table 2 Clinical characteristics and the results of laboratory investigations of Patient 2

\begin{tabular}{|c|c|}
\hline Factor & Value/level \\
\hline \multicolumn{2}{|l|}{ Clinical characteristics } \\
\hline Age (years) & 83 \\
\hline $\mathrm{BMI}$ & 20 \\
\hline Karnofsky score & 50 \\
\hline ECOG & 3 \\
\hline $\mathrm{BPs}(\mathrm{mmHg})$ & 143 \\
\hline $\mathrm{BPd}(\mathrm{mmHg})$ & 100 \\
\hline Heart rate (I/minute) & 97 \\
\hline Respiratory rate (I/minute) & 18 \\
\hline $\mathrm{SpO} 2(\%)$ on room air & 93 \\
\hline eGFR $\left(\mathrm{mL} / \mathrm{min} / I .73 \mathrm{~m}^{2}\right)^{*}$ & 87.26 \\
\hline \multicolumn{2}{|l|}{ Laboratory investigations } \\
\hline Albuminemia (g/L) & 26.20 \\
\hline WBC (10e9/L) & 15.14 \\
\hline $\mathrm{Hb}(\mathrm{mM})$ & 7.40 \\
\hline HTC (L/L) & 0.37 \\
\hline PLT (I0e9/L) & 261 \\
\hline Creatinine in serum $(\mu M)$ & 100.9 \\
\hline Urea in serum $(\mathrm{mM})$ & 5.90 \\
\hline Calcium in serum (mM) & 2.07 \\
\hline ALAT (U/L) & 25 \\
\hline AspAT (U/L) & 16 \\
\hline PT time (seconds) & 12.60 \\
\hline PT indicator (\%) & 86.50 \\
\hline INR & 1.20 \\
\hline
\end{tabular}

Note: *eGFR was calculated by the MDRD formula.

Abbreviations: ALAT, alanine aminotransferase; AspAT, aspartate aminotransferase; BMI, body mass index; BPs, systolic blood pressure; BPd, diastolic blood pressure; ECOG, Eastern Cooperative Oncology Group scale performance score; eGFR, estimated glomerular filtration rate; Hb, hemoglobin; HTC, hematocrit; INR, international normalized ratio; MDRD, Modification of Diet in Renal Disease formula; PLT, platelets; PT, prothrombin; SpO2, blood oxygen saturation; WBC, white blood cells. lower extremities were swollen, with crural varices. Clinical characteristics of the patient and laboratory tests results are presented in Table 2.

\section{Pertinent medical history}

Ovarian cancer was diagnosed 2 years before admission to the hospice unit, and bilateral adnexa removal was performed. One year before admission, a malignant infiltration on the rectum and metastases to the liver were detected. Subsequently, the patient started complaining about vertigo. No brain metastases were revealed in the computed tomography scan.

\section{Concominant diseases}

The patient also had arterial hypertension, angina pectoris, sustained atrial fibrillation, and vertigo.

\section{Drugs taken prior to admission}

Prior to admission the patient took the following drugs: oxycodone $60 \mathrm{mg}$ orally in divided doses, buprenorphine transdremal formulation releasing $50 \mathrm{mcg} / \mathrm{h}$, perindopril $5 \mathrm{mg}$ orally daily, valsartan $160 \mathrm{mg}$ orally daily, bisoprolol $2.5 \mathrm{mg}$ orally daily, amiodarone $200 \mathrm{mg}$ orally twice a day, pantoprazole $20 \mathrm{mg}$ orally daily.

\section{Hospice treatment}

A surgical treatment of the gastrointestinal tract metastases was suggested but the patient refused to approve it. After the surgical examination, mild proctorrhagia occurred. The symptomatic and antihemorrhagic treatment was introduced, together with enemas. Proctorrhagia receded, but the patient's condition worsened and the tenesmoid pain intensity increased. Morphine sulfate, ketamine, midazolam, and metoclopramide by constant subcutaneous infusion (pump) were introduced with little effect. The patient felt unwell and reported confusion. Consequently, ketamine was discontinued. The other drugs' doses and modes of administration were modified, and muscle relaxants were introduced; however, all of these procedures had little effect. Interventional doses of spasmalgon IV, morphine sulphate IV, and midazolam IV were also ineffective. Amitriptyline was not introduced due to potential cardiotoxicity. Gabapentin escalated vertigo. The pain intensified and the symptoms were sudden and violent, but the patient was able to walk. As the patient did not accept invasive pain management, we decided to administer test dose(s) of bupivacaine rectally.

\section{Methods}

The study was approved by the Bioethical Committee at the Poznan University of Medical Sciences, and written 
informed consent was obtained from the patients. Intrathecal (Case 1) and rectal (Case 2) bupivacaine administrations were performed. Vital signs, blood oxygen saturation $(\mathrm{SpO} 2)$ in room air, blood pressure (BP), and heart rate (HR) were monitored regularly before, during, and after the procedures.

Pain was rated by the patient by means of the $0-10$ VRS (0: no pain, 10: worst imaginable pain).

Possible drug-drug interaction(DDI) screening: DDIs were indentified by means of the Facts and Comparisons eAnswers, version 4.0 software (http://www.factsandcomparisons. com; Facts and Comparisons, St Louis, MO, USA). The software classifies potential DDIs by the level of severity (1: major, 2: moderate, 3 : minor), onset (rapid, delayed), and scientific evidence (1: established, 2: probable, 3: suspected, 4: possible, 5: unlikely).

\section{Case I}

Hyperbaric ("heavy"), small volume bupivacaine solution (2 $\mathrm{mL}$ of $0.25 \%-0.5 \%$ ), containing $80 \mathrm{mg} / \mathrm{mL}(8 \%)$ of glucose (bupivacaine WZF spinal $0.5 \%$ heavy; Warsaw Pharmaceutical Company, Polfa Warszawa, Warszawa, Poland) was used for the intrathecal boluses, at the L2-L3 level. The patient had the procedure performed in the lateral position and was placed in a supine position immediately thereafter. An externalized tunneled intrathecal catheter was percutaneously placed into the intrathecal (subarachnoid) space, at the lumbar L2-L3 level, for repeated injections of bupivacaine, to allow for a prolonged block. Propofol IV (1 $\mathrm{mg} / \mathrm{kg}$ ) was administered prior to the intrathecal catheter installation. The patient was placed in a lateral decubitus position, and prepped and draped aseptically. The skin area was prepared with a betadine (Purdue Pharma LP, Stamford, CT, USA) solution. The level of the spinous process (L2/L3) was determined. Infiltration anesthesia with $2 \%$ lignocaine solution was delivered to the place where the needle was subsequently inserted. Next, the SPINOCATH $18 \mathrm{G}$ introducer needle (B/Braun, Medtronic, Minneapolis, MN, USA) supplied with an InDura catheter kit (Medtronic, Inc., Minneapolis, MN, USA) was inserted into the skin in a paramedian entry point between L2 and L3, and advanced into the epidural space, which was identified with the loss of resistance technique. Next, the introducer needle was advanced until the dura was penetrated and free-flowing CSF was noticed. Once the catheter reached the intrathecal space, the stylet was removed. The catheter exit site was marked with a small incision and the needle was removed to be subsequently inserted again, laterally, $10 \mathrm{~cm}$ from (and with the tip pointing at) the exit site. Next, the catheter was passed through the introducer needle and the needle was detached. Steri-strips and a Tegaderm dressing (3M Company, Maplewood, MN, USA) were used to secure the catheter exit site, and a 2-0 silk and V-winged anchor was applied to keep the catheter attached to the skin.

During the procedure, BP remained constant, within the normal range, but it dropped suddenly 3 minutes after the administration of bupivacaine: from $124 / 71 \mathrm{mmHg}$ (HR: 89 beats per minute; SpO2 88\%) to $96 / 56 \mathrm{mmHg}$ (HR 91 beats per minute, SpO2 85\%). Thus, ephedrinum hydrochloricum $25 \mathrm{mg}$ IV and hydroxyethyl starch $500 \mathrm{~mL}$ IV were administered. Consequently, BP increased to $162 / 81 \mathrm{mmHg}$ and remained within the normal range (142/95 to $151 / 90 \mathrm{mmHg}$ ) for the next 6 hours. SpO2 before the procedure and after the ephedrine administration ranged from 92\%-93\%. No electrocardiogram (ECG) changes induced by the bupivacaine administration were observed.

\section{Case 2}

Patient 2 was administered $100 \mathrm{~mL}$ of the $0.05 \%-0.1 \%$ bupivacaine hydrochloride (Claris Lifesciences Ltd, Ahmedabad, India) solution rectally (50-100 $\mathrm{mg}$ of bupivacaine; $0.5-1.0 \mathrm{mg} / \mathrm{mL}$ ). During the procedure, after the first and second bupivacaine administration, no side effects, no complications, and no ECG changes were noticed. BP and HR remained within the normal range (142/95 to $151 / 90 \mathrm{mmHg}$, 86 beats per minute), and $\mathrm{SpO} 2$ before and during the procedure ranged from $92 \%-93 \%$. The enemas were not immediately followed by defecation.

\section{Total bupivacaine plasma level determination Case I}

Blood samples (2-3 mL each) from the central vein catheter were taken 30 minutes, 1 hour, 6 hours, and 7 hours after the first bupivacaine bolus; 6 hours after the second bolus; and 6 hours after the third bolus. Blood samples were centrifuged and plasma was separated and stored at $-60^{\circ} \mathrm{C}$ before assay. Total bupivacaine plasma concentrations were determined using the high-performance liquid chromatography-ultraviolet (HPLC-UV) method.

\section{Case 2}

As in Case 1, blood samples from the central vein catheter were taken 30 minutes, 1 hour, and 6 hours after the first bupivacaine bolus, and 30 minutes, 1 hour, 6 hours, and 12 hours after the second bolus. 
Case 1: Bupivacaine administered intrathecally

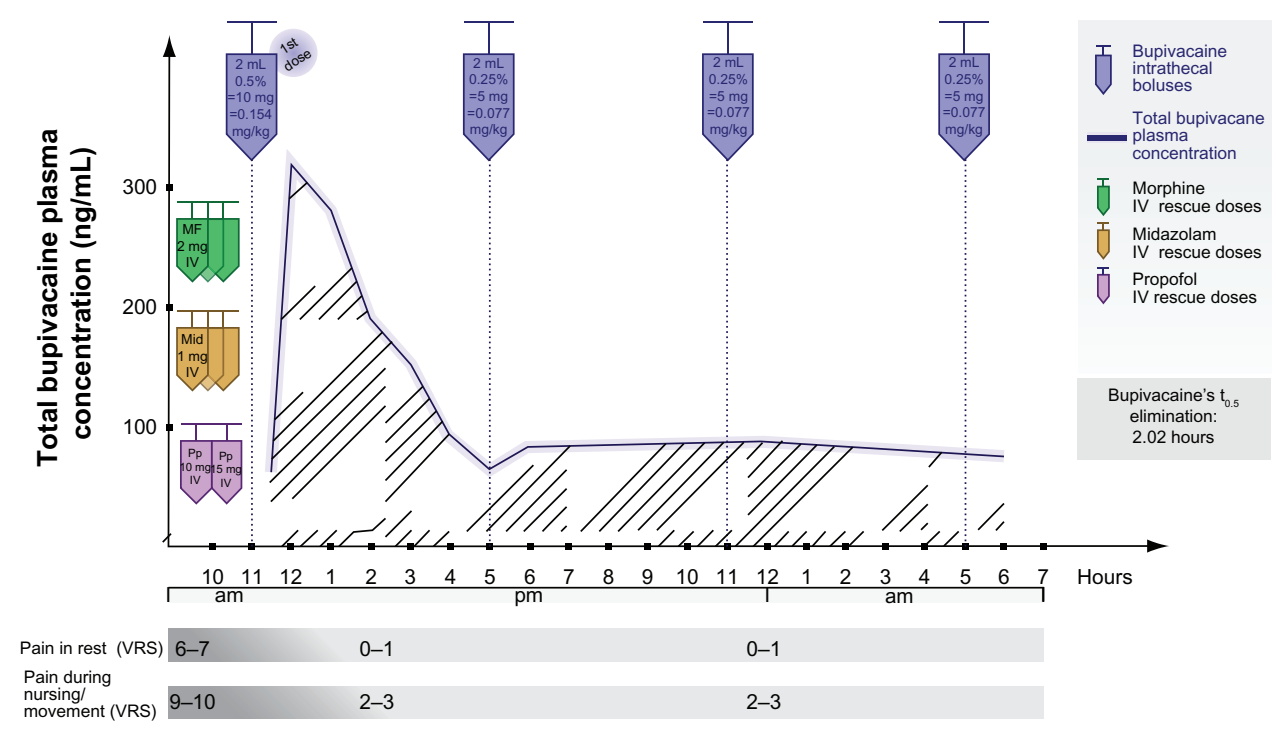

Figure I Bupivacaine administered intrathecally in Case I.

Abbreviations: IV, intravenous; $\mathrm{t}_{0,5}$, elimination half-life; VRS, Verbal Rating Scale; MF, morphine sulphate; Mid, Midazolam; Pp, Propofol.

\section{Results}

Case I

The first bupivacaine intrathecal bolus reduced pain significantly within 2-3 minutes (Figure 1), but caused a drop in $\mathrm{BP}$ at nearly the same time. The next boluses contained a half of the first Bupivacaine dose and relieved pain in rest and during nursing excellently. Meanwhile, it had less impact on $\mathrm{BP}$, which remained in the range of $135 / 84$ to $140 / 70 \mathrm{mmHg}$ for the following 3 hours. Then it declined and remained around 104/60 mmHg (HR around 90 beats per minute) for the next days. SpO2 after the procedures ranged $87 \%-89 \%$. The onset of maximal analgesia was observed 2-3 minutes after the boluses. The duration of analgesia was 6 hours. Total daily bupivacaine dose was $25 \mathrm{mg}$. The bupivacaine plasma concentrations ranged from 67.5 to $317.2 \mathrm{ng} / \mathrm{mL}$. The elimination rate constant $\left(\mathrm{K}_{\mathrm{e}}\right)$ for bupivacaine was $0.344 \mathrm{~L} /$ hour. The patient did not want to respond to requests, and no active movements of lower extremities were observed. No ECG

Case 2: Bupivacaine administered rectally

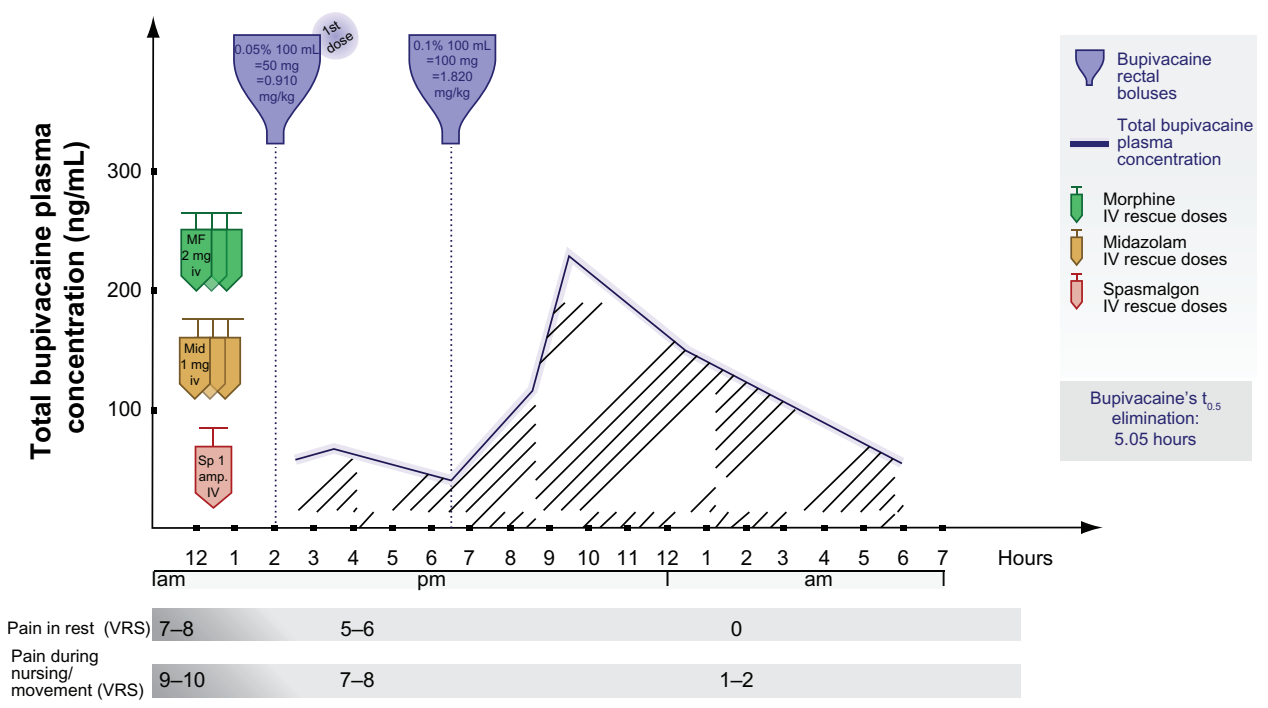

Figure 2 Bupivacaine administered rectally in Case 2.

Abbreviations: IV, intravenous; $\mathrm{t}_{0.5}$, elimination half-life; VRS, Verbal Rating Scale; Sp, Spasmalgon; amp, ampule; Mid, Midazolam; MF, morphine sulphate. 
changes or other signs of bupivacaine toxicity induced by the drug were detected.

In Case 1, the following potential DDIs were identified: ketoprofen-enoxaparin (severity: major, onset: rapid, level of evidence: 3), ketoprofen-lithium carbonate (severity: moderate, onset: delayed, level of evidence: 1), fentanylpropofol (severity: minor, onset: rapid, level of evidence: 5).

\section{Case 2}

The first bupivacaine dose reduced pain by $25 \%$ at rest and by $20 \%$ during movements within 12-15 minutes following dosage (maximal analgesia) (Figure 2). That is why the next bupivacaine dose was doubled. It improved pain control satisfactorily within 10 minutes (Figure 2). The duration of analgesia was 4.5 hours for the first enema and 11 hours for the second one. Bupivacaine plasma concentrations remained within the range of $46.5-235.7 \mathrm{ng} / \mathrm{mL}$ following both boluses. Total daily bupivacaine dose equaled $150 \mathrm{mg}$. $\mathrm{K}_{\mathrm{e}}$ for bupivacaine was $0.125 \mathrm{~L} /$ hour. After the first and the second bupivacaine doses, no side effects, complications, or additional ECG changes were noticed. $\mathrm{BP}$ and $\mathrm{HR}$ remained within the range of $131 / 73$ to $166 / 106 \mathrm{mmHg}$ and $79-113$ beats per minute, respectively. $\mathrm{SpO} 2$ ranged from $88 \%-92 \%$ after the procedures. The patient was able to sit and walk (no motor block/paralysis was observed).

In Case 2, the following potential DDIs were identified: ketamine-amiodarone (severity: major, onset: rapid, level of evidence: 3), fentanyl-amiodarone (severity: major, onset: rapid, level of evidence: 4), amlodipine-valsartan (severity: moderate, onset: delayed, level of evidence: 3), perindopril-valsartan (severity: moderate, onset: delayed, level of evidence: 3), bupivacaine-bisoprolol (severity: moderate, onset: rapid, level of evidence: 4).

\section{Discussion}

The patient-oriented approach, focusing on individual satisfaction and the quality of life and dying, is crucial in the terminal stage of a cancer disease. Both cases present significant pain relief achieved with two different (but both successful) administration methods of bupivacaine (intrathecal versus rectal) (Figures 1 and 2).

In Case 2, maximal pain relief was observed 10-15 minutes after the bupivacaine enemas, similarly to ten subjects with irritable bowel syndrome described by Verne et al, for whom rectal lidocaine reduced pain in 5-15 minutes (maximum effect after the onset of treatment). ${ }^{33}$ The effect in Case 2 was dose-dependent: the dose of $100 \mathrm{mg} / \mathrm{mL}$ was more effective and persisted longer than the $50 \mathrm{mg} / \mathrm{mL}$ dose (Figure 2).
In Case 1, both intrathecal bupivacaine doses relieved pain substantially (Figure 1), but the first, higher dose (2 mL of the $0.5 \%$ solution) caused a drop in systemic BP by around $22 \%$. This unwanted effect was successfully managed and the next doses were smaller (Figure 1). Three hours after the second dose, BP declined but remained $>100 / 60 \mathrm{mmHg}$ for the next days during bupivacaine administration. After bupivacaine introduction, $\mathrm{SpO} 2$ decreased slightly in both cases (by $1 \%$ in Case 1 and by $1 \%-4 \%$ in Case 2).

An LA, injected intrathecally into the lumbar region, may block sympathetic outflow, and, via venous pooling in the legs, cause hypotension. The response to spinal analgesia may be influenced by a patient's age.$^{34}$ For instance, the effects of subarachnoid administration of hyperbaric bupivacaine have been shown to change in the elderly. ${ }^{35,36}$ The subarachnoid blockade was reported to reach three to four segments higher in older adults (when compared to younger adults $[<60$ years old]). Advanced age and high analgesia levels increase the risk of hypotension resulting from spinal analgesia. ${ }^{37}$ The severity of hypotension depends on the level of sympathetic block, which extends two to four segments further than the sensory block. ${ }^{38}$ For the sake of the patient's safety, the level of a sympathetic block should be kept low. The elderly, the very weak, and patients with cardiovascular and/or liver diseases should have their bupivacaine dosage carefully titrated and limited. There are no reliable data on the recommended dosage for renal patients.

Intrathecal doses should constitute $10 \%-20 \%$ of the epidural ones, ${ }^{8}$ which makes the doses in Case 1 equal to $25 \%-50 \%$ of those described by Lapmahapaisan et al. ${ }^{39}$ The total daily intrathecal bupivacaine dose should remain less than $30-60 \mathrm{mg}$ (which is equal to $6-12 \mathrm{~mL}$ of the $0.5 \%$ solution). ${ }^{15}$ In the case described by Kurihara et al, intrathecal analgesia for cancer pain with a single dose of $36 \mathrm{mg}$ of bupivacaine was successful and safe. ${ }^{40}$ The total daily intrathecal bupivacaine dose in Case 1 was $25 \mathrm{mg}$ (Figure 1).

There are no recommendations for rectal use of bupivacaine. Any bupivacaine local infiltration dose should be kept below the maximum one, which is $400 \mathrm{mg}$ daily. The total daily rectal bupivacaine dose in Case 2 was $150 \mathrm{mg}$ (Figure 2). The patient in Case 2 received $37.5 \%$ of the maximum recommended daily dose, so even considering that the dosage should be adjusted for age and condition, $150 \mathrm{mg}$ per day was a relatively small dose. LAs' systemic bioavailability after their rectal administration is high. In a study by de Boer et al, six healthy subjects had their mean rectal systemic availability equal to $67 \%$, versus $27 \%$ after oral intake (measurement based on plasma concentrations), 
with small intra-individual variability. ${ }^{31}$ Several factors determine the systemic absorption of LA from the site of administration. These include the site of application, local tissue vascularity, dosage, and hepatic "first-pass" effect (partially avoided after rectal administration). On the other hand, bupivacaine's bioavailability after its rectal administration remains understudied, both in healthy volunteers and in patients with rectal inflammations or malignancies. Theoretically, a rectal drug administration should lead to similar plasma levels as the oral route. However, there are a limited amount of data confirming this assumption. A given drug's formulation seems to be crucial for the effect. ${ }^{32}$

In the cases presented, the total plasma bupivacaine concentrations remained within the safe ranges: 65.7-317.2 ng/mL in Case 1 and 46.5-235.7 ng/mL in Case 2 . In the Lapmahapaisan et al study on 25 patients with spinal anesthesia, $20 \mathrm{~mL}$ of $0.5 \%$ bupivacaine generated plasma drug concentrations equal to $176.30-1,383.99 \mathrm{ng} / \mathrm{mL}$ and was safe. ${ }^{39}$ In our previous study, ${ }^{42}$ a paravertebral blockage with $12.5-50 \mathrm{mg}$ of bupivacaine in boluses (total daily dose was $137.50 \mathrm{mg}$ ) caused total plasma drug concentration to range from $22.9-573.5 \mathrm{ng} / \mathrm{mL}$ and provided for a safe, effective analgesia. On the other hand, bupivacaine concentrations in the $810-2,700 \mathrm{ng} / \mathrm{mL}$ range caused mild CNS toxicity (facial tingling, tinnitus, visual disturbances) in normal humans after IV bupivacaine infusion. ${ }^{43}$ The mode of administration, total daily dose, plasma concentrations, and individual differences in the tolerance to elevated bupivacaine plasma levels may all affect the safety of treatment. ${ }^{22-24}$ In the studies presented in this paper, bupivacaine's elimination was slower after its rectal administration (Case 2) than after the intrathecal boluses (Case 1) ( $\mathrm{K}_{\mathrm{e}}$ was 0.125 versus 0.344 , respectively). When an amide LA is given rectally, the "first-pass" hepatic elimination is partially avoided..$^{31,44}$ Similarly to our results, de Boer et al calculated that the elimination half-life $\left(\mathrm{t}_{0.5}\right)$ of lidocaine was slightly longer after rectal administration than after intravenous and oral administrations..$^{31}$ In a study by Bowdle et al on six normal humans, bupivacaine (30-50 $\mathrm{mg}$ IV) $\mathrm{t}_{0.5}$ was 2.6 hours in controls and 4.9 hours in subjects pretreated with propranolol $40 \mathrm{mg}$ every 6 hours orally (bupivacaine hepatic clearance was increased by $35 \%){ }^{43}$

Bupivacaine hepatic elimination is determined by several factors; for instance, by liver functioning, hepatic blood flow, and the coadministration of drugs affecting microsomal P450 enzymes and cardiac output.

In Case 2, the DDI between ketamine and amiodarone could have decreased cardiac output, while the interaction between fentanyl and amiodarone may have caused negative inotropic and chronotropic effects. The reduction of cardiac output could have also been reduced due to atrial fibrillation. The decrease in cardiac output, followed by reduced hepatic blood flow, could have been the reason for slower bupivacaine elimination in Patient 2. In Case 1, DDIs could have increased the risk of bleeding (ketoprofen-enoxaparin), convulsions, or asystole (fentanyl-propofol).

One major disadvantage of the rectal administration of bupivacaine may be related to a potential discomfort for the patient and a defecation reflex induced by enema. However, rectal bupivacaine boluses may serve as an alternative to the invasive method of tenesmoid pain management.

\section{Limitations}

The study had the following limitations:

- small number of cases,

- interpatient variability factor: patients' status (Karnofsky score of 30 versus 50), different organ reserves, comorbidities, and drugs coadministered,

- in the case of rectal bupivacaine administration: potential outflow of a small part of the infusion, resulting in slightly less drug absorbed (than predicted and calculated), and

- in Case 2: potential alteration of the drug's bioavailability resulting from tissue/mucous deterioration.

\section{Conclusion}

1. Intrathecal boluses of $2 \mathrm{~mL} 0.25 \%$ solution of bupivacaine every 6 hours was a safe, effective method of intractable pain management in an elderly, terminally ill cancer patient (Case 1). Total daily bupivacaine dose was relatively small, plasma total concentrations were safe. The $t_{0.5}$ of bupivacaine in Case 1 was comparable to the $\mathrm{t}_{0.5}$ of bupivacaine in healthy volunteers. The bolus of bupivacaine $2 \mathrm{~mL} 0.5 \%$ caused a drop in BP.

2. Rectal boluses of the $100 \mathrm{~mL} 0.1 \%$ bupivacaine solution relieved an intractable, tenesmoid cancer pain in a terminally ill, elderly patient (Case 2) safely and significantly. The total daily bupivacaine dose was six times higher than during IDD, but the maximal plasma total bupivacaine concentrations were smaller. Bupivacaine $\mathrm{t}_{0.5}$ was prolonged in Case 2, probably due to DDIs.

3. The onset and duration of effective analgesia following both intrathecal and rectal bupivacaine administration was acceptable.

4. In contrast to rectal administration, intrathecal administration of bupivacaine created a risk of decline in BP during the treatment. 
5. DDIs can significantly alter bupivacaine's elimination. They should be analyzed individually during any bupivacaine treatment.

6. Bupivacaine enemas were an effective, safe method of severe, intractable, tenesmoid pain management in a terminally ill elderly cancer patient.

\section{Acknowledgment}

This study is published with the written consent of the patients. The authors would also like to thank Ms Katarzyna Stachowiak, MA, MSc, for her contribution in preparing the graphic material and her help in translation.

\section{Disclosure}

The authors report no conflicts of interest in this work.

\section{References}

1. World Health Organization. Cancer Pain Relief. Second Edition. Geneva: World Health Organization; 1996. Available from: http://whqlibdoc.who. int/publications/9241544821.pdf. Accessed June 9, 2014.

2. Ventafridda V, Tamburini M, Caraceni A, De Conno F, Naldi F. A validation study of the WHO method for cancer pain relief. Cancer. 1987;59(4):850-856.

3. Zech DF, Grond S, Lynch J, Hertel D, Lehmann KA. Validation of World Health Organization Guidelines for cancer pain relief: a 10-year prospective study. Pain. 1995;63(1):65-76.

4. Lema MJ. Invasive procedures for cancer pain. Pain Clin Update. 1998;6(1):1-8

5. Kaplan R. Positioning of interventional pain therapies requires balancing of risks and benefits and consideration of goals of care. J Support Oncol. 2010;8(2):62-63.

6. Brogan S, Junkins S. Interventional therapies for the management of cancer pain. J Support Oncol. 2010;8(2):62-63.

7. Vargas-Schaffer G. Is the WHO analgesic ladder still valid? Twenty-four years of experience. Can Fam Physician. 2010;56(6): 514-517. e202.

8. Sloan PA. The evolving role of interventional pain management in oncology. J Support Oncol. 2004;2(6):491-500, 503.

9. Plancarte R, Alvarez J, Arrieta MC. Interventional treatment of cancer pain. Semin Pain Med. 2003;1(1):34-42.

10. Christo PJ, Mazloomdoost D. Interventional pain treatments for cancer pain. Ann N Y Acad Sci. 2008;1138:299-328.

11. Ripamonti CI, Santini D, Maranzano E, Berti M, Roila F; ESMO Guidelines Working Group. Management of cancer pain: ESMO Clinical Practice Guidelines. Ann Oncol. 2012;23(Suppl 7):139-154.

12. Raphael J, Hester J, Ahmedzai S, et al. Cancer pain: part 2: physical, interventional and complimentary therapies; management in the community; acute, treatment-related and complex cancer pain: a perspective from the British Pain Society endorsed by the UK Association of Palliative Medicine and the Royal College of General Practitioners. Pain Med. 2010;11(6):872-896.

13. Kedlaya D, Reynolds L, Waldman S. Epidural and intrathecal analgesia for cancer pain. Best Pract Res Clin Anaesthesiol. 2002;16(4): 651-665.

14. Mercandante S, Portenoy RK. Opioid poorly-responsive cancer pain. Part 3. Clinical strategies to improve opioid responsiveness. J Pain Symptom Manage. 2001;21(4):338-354.

15. Hicks F, Simpson KH. Spinal drug delivery. In: Hicks F, Simpson KH. Nerve Blocks in Palliative Care. Oxford: Oxford University Press; 2004;91-114.
16. Gilmer-Hill HS, Boggan JE, Smith KA, Frey CF, Wagner FC, Hein LJ. Intrathecal morphine delivered via subcutaneous pump for intractable pain in pancreatic cancer. Surg Neurol. 1999;51(1):6-11.

17. Walker SM, Goudas LC, Cousins MJ, Carr DB. Combination spinal analgesic chemotherapy: a systematic review. Anesth Analg. 2002;95(3):674-715.

18. Togal T, Demirbilek S, Koroglu A, Yapici E, Ersoy O. Effects of S(+) ketamine added to bupivacaine for spinal anaesthesia for prostate surgery in elderly patients. Eur J Anaesthesiol. 2004;21(3):193-197.

19. Stoelting RK, Miller RD. Spinal and epidural anesthesia. In: Stoelting RK, Miller RD, editors. Basics of Anesthesia. 4th ed. Philadelphia: Churchill Livingstone; 2000:168-195.

20. Smith TJ, Staats PS, Deer T, et al; Implantable Drug Delivery Systems Study Group. Randomized clinical trial of an implantable drug delivery system compared with comprehensive medical management for refractory cancer pain: impact on pain, drug-related toxicity, and survival. J Clin Oncol. 2002;20(19):4040-4049.

21. Hayek SM, Deer TR, Pope JE, Panchal SJ, Patel VB. Intrathecal therapy for cancer and non-cancer pain. Pain Physician. 2011;14(3):219-248.

22. Knudsen K, Beckman Suurküla M, Blomberg S, Sjövall J, Edvardsson N. Central nervous and cardiovascular effects of iv infusions of ropivacaine, bupivacaine and placebo in volunteers. Br J Anaesth. 1997;78(5):507-514.

23. Aguilera IM, Vaughan RS. Calcium and the anaesthetist. Anaesthesia. 2000;55(8):779-790.

24. Fagenholz PJ, Bowler GMR, Carnochan FM, Walker WS. Systemic local anaesthetic toxicity from continuous thoracic paravertebral block. $\mathrm{Br} J$ Anaesth. 2012;109(2):260-262.

25. Cox B, Durieux ME, Marcus MAE. Toxicity of local anaesthetics. Best Pract Res Clin Anaesthesiol. 2003;17(1):111-136.

26. Dillane D, Finucane BT. Local anesthetic systemic toxicity. Can J Anaesth. 2010;57(4):368-380.

27. Neal JM1, Bernards CM, Butterworth JF 4th, et al. ASRA practice advisory on local anesthetic systemic toxicity. Reg Anesth Pain Med. 2010;35(2):152-161.

28. Richardson J, Lönnqvist PA, Naja Z. Bilateral thoracic paravertebral block: potential and practice. Br J Anaesth. 2011;106(2):164-171.

29. Gantenbein M, Attolini L, Bruguerolle B, et al. Oxidative metabolism of bupivacaine into pipecolylxylidine in humans is mainly catalyzed by CYP3A. Drug Metab Dispos. 2000;28(4):383-385.

30. Smith T. Local anaesthetic agents. In: Smith T, Pinnock C, Lin T, editors. Fundamentals of Anaesthesia. 3rd ed. Cambridge: Cambridge University Press; 2009:620-631.

31. de Boer AG, Breimer DD, Mattie H, Pronk J, Gubbens-Stibbe JM. Rectal bioavailability of lidocaine in man: partial avoidance of "first-pass" metabolism. Clin Pharmacol Ther. 1979;26(6):701-709.

32. de Boer AG, Moolenaar F, de Leede LG, Breimer DD. Rectal drug administration: clinical pharmacokinetic considerations. Clin Pharmacokinet. 1982;7(4):285-311.

33. Verne NG, Robinson ME, Vase L, Price DD. Reversal of visceral and cutaneous hyperalgesia by local rectal anesthesia in irritable bowel syndrome (IBS) patients. Pain. 2003;105(1-2):223-230.

34. Racle JP, Benkhadra A, Poy JY, Gleizal B. Spinal analgesia with hyperbaric bupivacaine: influence of age. Br J Anaesth. 1988;60(5): 508-514.

35. Veering BT, Burm AG, Spierdijk J. Spinal anesthesia with hyperbaric bupivacaine. Effects of age on neural blockade and pharmacokinetics. Br J Anaesth. 1988;60(2):187-194.

36. Veering BT, Burm AG, Vletter AA, van den Hoeven RA, Spierdijk J. The effect of age on systemic absorption and systemic disposition of bupivacaine after subarachnoid administration. Anesthesiology. 1991;74(2):250-257.

37. Carpenter RL, Caplan RA, Brown DL, Stephenson C, Wu R. Incidence and risk factors for side effects of spinal anesthesia. Anesthesiology. 1992;76(6):906-916.

38. Chamberlain DP, Chamberlain BD. Changes in the skin temperature of the trunk and their relationship to sympathetic blockade during spinal anesthesia. Anesthesiology. 1986;65(2):139-143. 
39. Lapmahapaisan S, Chinachoti T, Kongpatanakul S, et al. Plasma concentrations of bupivacaine after spinal anesthesia with single shot femoral nerve block in total knee arthroplasty. J Med Assoc Thai. 2013;96(3):312-317.

40. Kurihara Y, Ikegaki J, Kato H, Chigusa S, Kaetsu H. [Intrathecal segmental analgesia with a single dose of bupivacaine for cancer pain in the abdominal wall]. Masui. 2008;57(2):182-186. Japanese.

41. Murphy NG, Benowitz NL. Anesthetics, Local. In: Olson KR, editor. Poisoning and Drug Overdose. 5th ed. New York: Lange Medical Books/ McGraw-Hill; 2007;76.
42. Zaporowska-Stachowiak I, Kotlińska-Lemieszek A, Kowalski G, et al. Lumbar paravertebral blockade as intractable pain management method in palliative care. Onco Targets Ther. 2013;6:1187-1196.

43. Bowdle TA, Freund PR, Slattery JT. Propranolol reduces bupivacaine clearance. Anesthesiology. 1987;66(1):36-38.

44. de Leede LG, de Boer AG, Roozen CP, Breimer DD. Avoidance of "firstpass" elimination of rectally administered lidocaine in relation to the site of absorption in rats. J Pharmacol Exp Ther. 1983;225(1):181-185.

\section{Publish your work in this journal}

OncoTargets and Therapy is an international, peer-reviewed, open access journal focusing on the pathological basis of all cancers, potential targets for therapy and treatment protocols employed to improve the management of cancer patients. The journal also focuses on the impact of management programs and new therapeutic agents and protocols on

\section{Dovepress}

patient perspectives such as quality of life, adherence and satisfaction. The manuscript management system is completely online and includes a very quick and fair peer-review system, which is all easy to use. Visit http://www.dovepress.com/testimonials.php to read real quotes from published authors. 